REVIEW

\title{
Adverse health effects of prenatal and postnatal tobacco smoke exposure on children
}

\author{
W Hofhuis, J C de Jongste, P J F M Merkus
}

Arch Dis Child 2003;88:1086-1090

Parents who choose to smoke are possibly not aware of, or deny, the negative effects of passive smoking on their offspring. This review summarises a wide range of effects of passive smoking on mortality and morbidity in children. It offers paediatricians, obstetricians, specialists in preventive child health care, general practitioners, and midwives an approach to promote smoking cessation in smoking parents before, during, and after pregnancy.

See end of article for authors' affiliations

.......................

Correspondence to: Dr W Hofhuis, Erasmus MC, University Medical Centre Rotterdam, Sophia Children's Hospital, Rotterdam, Netherlands; w.hofhuis@erasmusmc.nl

Accepted 15 March 2003
$\mathrm{T}$ he adverse effects of passive smoking on the health of the fetus and child are thought to be common knowledge. Surprisingly, 15$37 \%$ of women still smoke while pregnant. ${ }^{1-3}$ Although the number of Dutch infants $(0-1$ year of age) exposed to environmental tobacco smoke (ETS) is decreasing, 36\% were exposed to ETS in their homes, 6\% during feeding, and $7 \%$ during car rides in 2000. ${ }^{4}$ Likewise, in the United States approximately $38 \%$ of children between 2 months and 5 years of age are exposed to ETS in the home. ${ }^{1}$ Even if a parent smokes outside the home, children could still face a high level of ETS exposure. ${ }^{5}$

\section{SMOKING AND PREGNANCY Obstetric complications}

An impressive amount of literature describes the adverse effects of smoking during pregnancy. Even before pregnancy, cigarette smoking is of influence since it is dose dependently associated with a decrease in fertility. ${ }^{67}$ Cigarette smoking during pregnancy is associated with a higher frequency of obstetric complications, such as spontaneous abortions, ${ }^{6}$ ectopic pregnancies, ${ }^{8}{ }^{9}$ preterm birth, ${ }^{10}$ placenta previa, abruptio placentae, and premature rupture of membranes. ${ }^{2}$ Smoking during pregnancy may be responsible for $15 \%$ of all preterm births and a $150 \%$ increase in overall perinatal mortality. ${ }^{2}$ Even in nonsmoking pregnant women, high exposure to ETS is associated with an increased risk for preterm birth. ${ }^{10} 11$ The relation between smoking and ectopic pregnancy might be causal, with a highly significant adjusted odds ratio of 2.5 or more for women who smoke more than 20 cigarettes a

\section{Intra-uterine lung growth}

Fetal breathing movements are essential for normal growth and structural maturation of the fetal lungs. ${ }^{13}$ Animal studies show that exposure to cigarette smoke during pregnancy leads to a reduction in fetal breathing movements. ${ }^{13}$ day. ${ }^{12}$
Prolonged absence or impairment of fetal breathing movements is likely to result in hypoplasia of the fetal lungs ${ }^{13}{ }^{14}$ with fewer saccules. ${ }^{15}$ This results in a reduced surface potentially available for gas exchange. ${ }^{15}$ Moreover, in utero cigarette smoke exposure decreased alveolar attachment points to the airways and caused changes in airway dimensions in guinea pigs. ${ }^{16}$ These observations may be applicable to humans since nicotine caused a reduction in the incidence of fetal breathing movements in normal and abnormal human pregnancies. ${ }^{17}$ Consequently, reduced lung growth in children of smoking mothers may begin antenatally..$^{15}$ Lung function tests in infants born to smoking mothers confirm reduced airway patency, ${ }^{18-20}$ whereas the effect of prenatal smoke exposure most likely plays a greater role on lung function in childhood than postnatal and childhood exposure. ${ }^{21}$ How long the impaired lung function that results from exposure in utero continues to be significant is still not known. ${ }^{22}$ Therefore, smoking during pregnancy might affect adult lung function, which is suggested to be "programmed" in fetal life. $^{23}$

\section{Low birth weight}

Active smoking by pregnant women induces early morphological changes of the placenta, ${ }^{24}$ resulting in a reduced volume of maternal intervillous space and a reduced volume and surface area of fetal capillaries. ${ }^{25}$ These morphological changes lead to a reduction in oxygen diffusion across the placenta and seem to be the result of an all-or-none effect, rather than a dose dependent effect. ${ }^{25}$ Hence, the fetus suffers from chronic hypoxic stress as a consequence of smoking. ${ }^{25} 26$ These factors contribute to a reduced birth weight and length, and a smaller head circumference at birth. ${ }^{27}{ }^{28}$ In developed countries maternal smoking is the major factor for low birth weight. ${ }^{28}$ It is estimated that smoking during pregnancy reduces birth weight by $10-15 \mathrm{~g}$ per cigarette smoked daily. ${ }^{29}$ However, this is not a linear relation; the sharpest declines in birth weight occurred at low levels of exposure. ${ }^{30}$ Therefore, the effect of a reduction of cigarette smoking during pregnancy is small compared to the effect of smoking cessation. It has even been suggested that high exposure to ETS in non-smoking pregnant

Abbreviations: $A D H D$, attention deficit and hyperactivity disorder; COPD, chronic obstructive pulmonary disease; ETS, environmental tobacco smoke; FEV, forced expiratory volume; SIDS, sudden infant death syndrome 
women is negatively associated with birth weight. $^{1031}$ Recently, Wang and co-workers concluded that the direct effects of smoking during pregnancy on birth weight and gestational age may even be stronger depending on the individual susceptibility. ${ }^{32}$ They investigated whether the association between maternal cigarette smoking and infant birth weight differs by polymorphisms of two maternal metabolic genes. Without consideration of genotype, continuous maternal smoking during pregnancy was associated with a mean reduction of $377 \mathrm{~g}$ in birth weight. When both metabolic genes were considered, the greatest reduction in birth weight $(-1285 \mathrm{~g})$ was found among smoking mothers with polymorphisms of both genes (which occurs in almost $10 \%$ of the population). Among never-smokers genotype did not independently confer an adverse effect. ${ }^{32}$

Although some women believe a low birth weight is associated with an easy delivery, they are unaware of the possible life-long consequences for their child. A low birth weight is associated with an increase in the incidence of coronary heart disease, stroke, hypertension, type 2 diabetes mellitus, insulin resistance, serum lipids, and premature pubarche (the Barker hypothesis). ${ }^{33}$ In non-industrialised countries these associations appear to be strongest. ${ }^{33}$

\section{Perinatal complications}

Smoking by the mother at any time during pregnancy is a risk factor for maternal colonisation of group B streptococcus, with a colonisation rate of $33 \%$ for smokers versus $16 \%$ for non-smokers. ${ }^{34}$ Chorioamnionitis, which has group B streptococcus as a key pathogen, is responsible for a significant number of midgestational abortions, ${ }^{35}$ abruptio placentae, ${ }^{36}$ preterm deliveries ${ }^{37}$ and infections, such as neonatal pneumonia and early neonatal sepsis. ${ }^{38-41}$ To our knowledge, there is no proven association between smoking during pregnancy and an increased incidence of chorioamnionitis. We speculate that the increase in perinatal complications in neonates from smoking mothers could be a direct result of an increase in chorioamnionitis.

\section{SMOKING AND CHILDREN}

\section{Sudden infant death syndrome}

Exposure to ETS during infancy is a major risk factor for sudden infant death syndrome (SIDS). A systematic review concluded that after adjusting for confounders, such as sleeping position and economic status, maternal smoking doubles the risk for SIDS. ${ }^{42}$ The effect of prenatal and postnatal smoking was similar. The relation is dose dependent and almost certainly causal. ${ }^{42}$

Prenatal smoking is almost invariably associated with postnatal smoking. Therefore, it is difficult to resolve the role of prenatal smoking per se using epidemiological studies. The fact that infants who died from SIDS had a higher nicotine concentration in their lung tissue compared with non-SIDS cases $^{43}$ supports the statement that postnatal ETS exposure is important. ${ }^{42}{ }^{43}$ Possible reasons for the association between passive smoking and SIDS are abnormalities in brain development, with a tendency to central apnoea ${ }^{44}$ and disturbed respiratory control mechanisms, ${ }^{42}$ including a reduced ventilatory response to hypoxia. ${ }^{45}$ Other possible explanations are an abnormal pulmonary development in neonates ${ }^{21}$ and the promotion of respiratory infections. ${ }^{46}$

\section{Infections}

In a systematic review a causal relation was found between parental smoking and an increased risk of acute lower respiratory illness in infancy. ${ }^{46}$ Most likely this is the result of both prenatal and postnatal passive smoking, but it is difficult to distinguish the independent contributions. On the other hand, the increased risk associated with smoking by other household members in families where the mother does not smoke suggests that exposure to ETS after birth contributes to acute chest illness in young children. ${ }^{46}$ There is a positive dose-response relation, which is stronger with maternal smoking compared to smoking by other household members. This is explained by a higher degree of postnatal exposure from the mother as principal care giver, and the fact that intra-uterine lung growth might already have been disturbed as a result of maternal smoking during pregnancy. ${ }^{46}$

In the first two years of life, passive smoking is associated with a higher incidence of respiratory infections in general, ${ }^{46}{ }^{47}$ including respiratory syncytial virus bronchiolitis. ${ }^{47} 48$ In addition, passive smoking is a risk factor for developing pulmonary tuberculosis in children immediately following infection, ${ }^{49}$ and a risk factor in meningococcal disease. ${ }^{5051}$ This could possibly be the result of a direct effect of cigarette smoke on host defences since smoking is negatively associated with cell mediated and humoral immunity, and smoking increases bacterial adherence and the risk of inflammation and other infections..$^{52-55}$ The observation that smokers are more likely to be carriers of meningococci is consistent with the increased risk of invasive meningococcal disease. ${ }^{56}$

\section{Middle ear disease and adenotonsillectomy in children}

In a systematic quantitative review, Strachan and Cook concluded that there is probably a causal relation between parental smoking and both acute and chronic middle ear disease in children. ${ }^{57}$ In particular, chronic middle ear disease is $20-50 \%$ more frequent in children exposed to ETS. There is no association between exposure to ETS and adenotonsillectomy in children. ${ }^{57}$ A possible explanation for the relation between ETS exposure and these and other infections, is a direct effect of cigarette smoke on host defences. ${ }^{54}$

\section{Lung function}

There is compelling evidence that maternal smoking reduces lung function in young children and that the effect is present at birth and attributable to effects of maternal smoking during pregnancy and early postnatal exposure on the child's lung development. ${ }^{58-60}$ In infants born to smoking mothers lung function tests show a reduction in forced expiratory flows compared to infants born to non-smoking mothers. ${ }^{18-20}$ This reduction in forced expiratory flows, used as a measure of airway patency, could amount to $51 \%$ compared to infants whose mothers did not smoke during pregnancy. ${ }^{18}$

In a pooled analysis of school age children, exposure to ETS was associated with a reduction of $1.4 \%$ in forced expiratory volume in one second $\left(\mathrm{FEV}_{1}\right)$. Parameters for airway patency of the peripheral airways, the mid and end expiratory flow rates, show a decrease of $5.0 \%$ and $4.3 \%$ respectively, in those exposed to ETS. ${ }^{60}$ These small, but significant, deficits in spirometric indices are almost certainly causally associated with maternal smoking, ${ }^{60}$ and much of the effect may be due to maternal smoking during pregnancy and/or neonatal exposure. ${ }^{21}{ }^{60}$ Smoking by the father only had no significant effect on the children's lung function. ${ }^{60} \mathrm{~A}$ dose-response relation was not always shown, perhaps due to the fact that parents tend to smoke less as their children develop respiratory symptoms. ${ }^{60}$ When the independent effect of prenatal and postnatal tobacco smoke exposure on children's lung function was studied, the effect of maternal smoking during pregnancy was larger than that of current smoking. ${ }^{6}$

\section{Wheezing and asthma}

Prenatal maternal smoking increases the risk for symptomatic paediatric asthma, ${ }^{62}$ and postnatal maternal smoking is associated with an increased incidence of wheezing illness up 
to the age of 6 years. ${ }^{63}$ Surprisingly, the long term prognosis of early wheezing illness was better if the mother smoked. The excess incidence of wheezing in smoking households appears to be largely non-atopic "wheezy bronchitis", which has a relatively benign prognosis. Therefore, postnatal ETS exposure can be considered as a co-factor provoking wheezing attacks, rather than a cause of the underlying asthmatic tendency. ${ }^{63}$ The reason why prenatal passive smoking is associated with paediatric asthma, and postnatal passive smoking is associated with non-atopic "wheezy bronchitis", remains to be elucidated. Possibly, a reduction in lung function as a result of prenatal passive smoking ${ }^{18-20}$ makes the children more susceptible for respiratory symptoms, and therefore enables the diagnosis of paediatric asthma. Furthermore, the distinction between wheezy bronchitis and asthma can be very difficult, and it seems conceivable that they can co-exist as well. Among children with established asthma, parental smoking is associated with more severe disease. ${ }^{63} 64$

In school age children (5-16 years), parental smoking has no influence on the prevalence of allergic asthma. Nevertheless, parental smoking does have an effect on respiratory symptoms, ${ }^{65}$ both in children with asthma and in children without asthma. Wheeze, cough, phlegm, and breathlessness are $20-40 \%$ more frequent in children exposed to ETS. ${ }^{65}$ There is a clear dose-response relation, which also becomes apparent when there is a reduction in symptoms as the parents stop smoking, and as the children grow older, and therefore spend less time with their parents. ${ }^{65}$

\section{Adult asthma and COPD}

A limited number of studies on passive smoking and asthma among adults have been published, showing that ETS exposure is associated with an increased risk of adult onset asthma.$^{66}$ Adults exposed to ETS at home or in the workplace have a $40-60 \%$ increased risk for asthma compared with adults who are not exposed. ${ }^{66}$

Chronic obstructive pulmonary disease (COPD) is not uncommon among non-smokers, suggesting that risk factors other than active cigarette smoking, including ETS, contribute to the development of COPD in non-smoking adults. ${ }^{66}$ The development of COPD in adults may result from impaired lung development and growth, premature onset of decline in lung function, and/or accelerated decline in lung function. ${ }^{67}{ }^{68}$ Impaired lung growth in utero from exposure to maternal smoking may begin a process that leads to the development of COPD. ${ }^{66}$ Exposure to ETS in infancy and childhood impairs lung growth, which limits the maximum level of lung function attained ${ }^{68}$ and possibly increases the risk for developing COPD. ${ }^{6}$ However, the effects of passive smoking on lung function have been inconsistent. If passive smoking causes a decrement in lung function the magnitude of the effect is small, which raises doubt about how this small effect could result in COPD. ${ }^{66}$

\section{Allergic sensitisation}

Several large studies failed to confirm early reports of a substantial or statistically significant association of maternal smoking with concentrations of total serum IgE in neonates or in older children. Similarly, no consistent association emerged between parental smoking and allergic rhinitis or eczema. Studies of an association between skin prick tests and parental smoking during pregnancy or infancy were broadly consistent in showing no adverse effect on skin test positivity. Given current evidence, it can be concluded that parental smoking, either before or immediately after birth, is unlikely to increase the risk of allergic sensitisation in children. ${ }^{69}$
Box 1: Associations of passive smoking

Proven associations of passive smoking affecting children*

- Increased incidence of obstetric complications ${ }^{2}$ 6-12

- Reduced birth weight ${ }^{10}$ 27-32

- Reduced head circumference at birth ${ }^{28}$

- Increased incidence of SIDS ${ }^{42}$

- Increased incidence of meningococcal infections ${ }^{50} 51$

- Increased incidence of acute lower airway infections $(0-3 \text { years })^{46}$

- Increased incidence of middle ear disease ${ }^{57}$

- Increased incidence of wheeze (0-5 years) ${ }^{63}$

- More frequent respiratory symptoms (5-16 years) ${ }^{63-65}$

- Persisting reduced lung function ${ }^{18-21} 58-61$

Possible associations of passive smoking in children

- Reduced and disturbed intra-uterine lung growth ${ }^{13-17}$

- Increased incidence of perinatal complications ${ }^{34-41}$

- Risk factor for neurodevelopmental and behavioural problems ${ }^{70-72}$

- Childhood cancer ${ }^{75-82}$

\section{No association of passive smoking in children*}

- Allergic sensitisation ${ }^{69}$

*Evidence in these groups is level II-2 evidence: "evidence obtained from well designed cohort or case-control analytical studies, preferably from more than one centre or research group $^{\prime \prime} .{ }^{83}$

\section{Neurodevelopmental and behavioural problems}

Epidemiological studies show that maternal smoking during pregnancy and postnatal ETS exposure could cause subtle changes in children's neurodevelopment and behaviour, such as reduced general intellectual ability and attention deficit and hyperactivity disorder (ADHD). ${ }^{70}$ However, studies to date are difficult to interpret because of the unknown influence of uncontrolled confounding factors. The precise impact of prenatal or postnatal exposure is not clear, ${ }^{70}$ however, there is consistent support for an aetiological role of prenatal smoking in the onset of antisocial behaviour. ${ }^{71}$ Moreover, there is a dose-response relation between maternal prenatal smoking and both criminal arrest and psychiatric hospitalisations for substance abuse in male and female offspring. ${ }^{72}$ Animal studies showed that the relation between nicotine and adverse developmental outcome is causal, ${ }^{73}$ and that prenatal nicotine exposure elicits abnormalities of cell proliferation and differentiation leading to shortfalls in the number of cells and altered synaptic activity. ${ }^{74}$ Possibly, these functional and structural adverse developments of the brain also occur in humans.

\section{Childhood cancer}

Although it has been suggested that there is an association between maternal smoking during pregnancy and childhood brain tumours, ${ }^{75}$ large case-control studies found no such association between childhood brain tumours and maternal smoking prior to pregnancy, active maternal smoking or exposure to ETS during pregnancy, ${ }^{76}{ }^{77}$ or passive smoking by the child during the first year of life. $^{78}$ For childhood leukaemia, studies are inconsistent. ${ }^{79} 80 \mathrm{~A}$ recent metaanalysis suggests a small increase in risk of all neoplasms, but not of specific neoplasms such as leukaemia and 


\section{Box 2: Most important effects of tobacco smoke exposure on children}

- Up to one third of the women smoke while pregnant

- Smoking during pregnancy is associated with:

- A higher frequency of obstetric and perinatal complications

- A low birth weight

- The effect of a reduction of cigarette smoking during pregnancy on birth weight is little compared to the effect of smoking cessation

- Maternal smoking during pregnancy is a possible risk factor for neurodevelopmental and behavioural problems in children

- Maternal smoking during or after pregnancy doubles the risk for SIDS

- Approximately one third of infants are exposed to environmental tobacco smoke

- Exposure to ETS is associated with increased frequency and severity of infections in children

- The association between passive smoking and childhood cancer remains controversial

- Passive smoking is an important risk factor for acute and chronic morbidity that can be avoided

childhood brain tumours. ${ }^{81}$ In conclusion, the potential association between passive smoking and childhood cancer remains a controversial topic with inconsistent results. ${ }^{75-82}$

\section{CONCLUSION AND IMPLICATIONS}

Prenatal and postnatal passive smoking have a wide range of effects on mortality and morbidity in children (boxes 1 and 2). Prenatal passive smoking has lifetime consequences since it influences placental and fetal development, reduces birth weight, and affects lung and brain development. A low birth weight is associated with an increase in the incidence of coronary heart disease, stroke, hypertension, type 2 diabetes mellitus, insulin resistance, serum lipids, and premature pubarche. Lung function tests in infants and older children born to smoking mothers show reduced airway patency, probably reflecting underdevelopment of lungs and airways. The reduced lung growth and the increased risk for respiratory infections due to passive smoking are possible explanations for the increased risk for SIDS. Furthermore, prenatal passive smoking is thought to be a risk factor for a variety of neurodevelopmental and behavioural problems, such as reduced general intellectual ability and attention deficit and hyperactivity disorder.

Postnatal exposure to ETS leads to more acute health effects, a twofold risk of SIDS, more frequent and more severe lower respiratory illnesses, and is a risk factor in adult onset asthma, middle ear disease, and meningococcal disease. Exposure to ETS is not a risk factor for allergic sensitisation, but children with and without asthma have more frequent respiratory symptoms, such as wheeze, cough, phlegm, and breathlessness.

Passive smoking is an important risk factor for acute and chronic, sometimes even lifelong, morbidity that can be avoided. A policy must be developed so that children are not exposed to ETS, prenatally or postnatally. This knowledge about the adverse health effects of involuntary smoke exposure to unborn and born children deserves more attention in the counselling of pregnant women and in campaigns aimed at the cessation of smoking.

\section{Authors' affiliations}

Ward H, J C de Jongste, P J F M Merkus, Erasmus MC, University Medical Centre Rotterdam, Sophia Children's Hospital, Rotterdam, Netherlands

\section{REFERENCES}

1 Gergen PJ, Fowler JA, Maurer KR, et al. The burden of environmental tobacco smoke exposure on the respiratory health of children 2 months through 5 years of age in the United States: Third National Health and Nutrition Examination Survey, 1988 to 1994. Pediatrics 1998;101:e8.

2 Andres RL, Day MC. Perinatal complications associated with maternal tobacco use. Semin Neonatol 2000;5:231-41.

3 Badlissi D, Guillemette A, Fadin A. [Prematurity and low birth weight: effects of active and passive smoking during pregnancy]. Can J Public Health $2001 ; 92: 272-5$.

4 NIPO. Continuous research smoking habits in the Netherlands 2000-IV. Amsterdam: Defacto, 2000.

5 Nelson R. Smoking outside still causes second-hand smoke exposure to children. Lancet 2002;359:1675.

6 Nash JE, Persaud TV. Embryopathic risks of cigarette smoking. Exp Pathol 1988;33(2):65-73.

7 Barbieri RL. The initial fertility consultation: recommendations concerning cigarette smoking, body mass index, and alcohol and caffeine consumption. Am J Obstet Gynecol 2001;185:1168-73.

8 Coste J, Job-Spira N, Fernandez H. Increased risk of ectopic pregnancy with maternal cigarette smoking. Am J Public Health 1991;81:199-201.

9 Bouyer J, Coste J, Fernandez H, et al. [Tobacco and ectopic pregnancy. Arguments in favor of a causal relation]. Rev Epidemiol Sante Publique 1998;46(2):93-9

10 Windham GC, Hopkins B, Fenster L, et al. Prenatal active or passive tobacco smoke exposure and the risk of preterm delivery or low birth weight. Epidemiology 2000;1 1:427-33.

11 Jaakkola JJ, Jaakkola N, Zahlsen K. Fetal growth and length of gestation in relation to prenatal exposure to environmental tobacco smoke assessed by hair nicotine concentration. Environ Health Perspect 2001;109:557-61.

12 Saraiya M, Berg CJ, Kendrick JS, et al. Cigarette smoking as a risk factor for ectopic pregnancy. Am J Obstet Gynecol 1998;178:493-8.

13 Harding R. Fetal pulmonary development: the role of respiratory movements. Equine Vet J Suppl 1997;(24):32-9.

14 Bassi JA, Rosso P, Moessinger AC, et al. Fetal growth retardation due to maternal tobacco smoke exposure in the rat. Pediatr Res 1984;18:127-30.

15 Collins MH, Moessinger AC, Kleinerman J, et al. Fetal lung hypoplasia associated with maternal smoking: a morphometric analysis. Pediatr Res 1985:19:408-12.

16 Elliot J, Carroll N, Bosco M, et al. Increased airway responsiveness and decreased alveolar attachment points following in utero smoke exposure in the guinea pig. Am J Respir Crit Care Med 2001;163:140-4.

17 Manning FA, Feyerabend $C$. Cigarette smoking and fetal breathing movements. Br J Obstet Gynaecol 1976:83:262-70.

18 Hanrahan JP, Tager IB, Segal MR, et al. The effect of maternal smoking during pregnancy on early infant lung function. Am Rev Respir Dis 1992;145:1129-35.

19 Hoo AF, Henschen M, Dezateux C, et al. Respiratory function among preterm infants whose mothers smoked during pregnancy. Am J Respir Crit Care Med 1998; 158:700-5

20 Dezateux C, Stocks J, Dundas I, et al. Impaired airway function and wheezing in infancy: the influence of maternal smoking and a genetic predisposition to asthma. Am J Respir Crit Care Med 1999;159:403-10.

21 Tager IB, Ngo L, Hanrahan JP. Maternal smoking during pregnancy. Effects on lung function during the first 18 months of life. Am J Respir Crit Care Med 1995; 152:977-83.

22 Le Souef PN. Pediatric origins of adult lung diseases. 4. Tobacco related lung diseases begin in childhood. Thorax 2000;55:1063-7.

23 Stein CE, Kumaran K, Fall CH, et al. Relation of fetal growth to adult lung function in south India. Thorax 1997;52:895-9.

24 Jauniaux $E$, Burton GJ. The effect of smoking in pregnancy on early placental morphology. Obstet Gynecol 1992;79(5 pt 1):645-8

25 Bush PG, Mayhew TM, Abramovich DR, et al. A quantitative study on the effects of maternal smoking on placental morphology and cadmium concentration. Placenta 2000;21:247-56.

26 Bush PG, Mayhew TM, Abramovich DR, et al. Maternal cigarette smoking and oxygen diffusion across the placenta. Placenta 2000;21:824-33.

27 Davies DP, Abernethy M. Cigarette smoking in pregnancy: associations with maternal weight gain and fetal growth. Lancet 1976:1:385-7.

28 Robinson JS, Moore VM, Owens JA, et al. Origins of fetal growth restriction. Eur J Obstet Gynecol Reprod Biol 2000;92:13-19.

29 Anderson GD, Blidner IN, McClemont S, et al. Determinants of size at birth in a Canadian population. Am J Obstet Gynecol 1984;150:236-44.

30 England U, Kendrick JS, Gargiullo PM, et al. Measures of maternal tobacco exposure and infant birth weight at term. Am J Epidemiol 2001;153:954-60.

31 Dejmek J, Solansk YI, Podrazilova K, et al. The exposure of nonsmoking and smoking mothers to environmental tobacco smoke during different gestational phases and fetal growth. Environ Health Perspect 2002;1 10:601-6.

32 Wang X, Zuckerman B, Pearson C, et al. Maternal cigarette smoking, metabolic gene polymorphism, and infant birth weight. JAMA 2002;287:195-202.

33 Barker DJ. In utero programming of chronic disease. Clin Sci (London) 1998;95:115-28. 
34 Terry RR, Kelly FW, Gauzer C, et al. Risk factors for maternal colonization with group B beta-hemolytic streptococci. J Am Osteopath Assoc 1999;99:571-3.

35 McDonald HM, Chambers HM. Intrauterine infection and spontaneous midgestation abortion: is the spectrum of microorganisms similar to that in preterm labor? Infect Dis Obstet Gynecol 2000;8:220-7.

36 Kramer MS, Usher RH, Pollack R, et al. Etiologic determinants of abruptio placentae. Obstet Gynecol 1997;89:221-6.

37 Ustun C, Kocak I, Baris S, et al. Subclinical chorioamnionitis as an etiologic factor in preterm deliveries. Int J Gynaecol Obstet 2001;72:109-15.

38 Newton ER. Chorioamnionitis and intraamniotic infection. Clin Obstet Gynecol 1993;36:795-808.

39 de Araujo MC, Schultz R, Vaz FA, et al. A case-control study of histological chorioamnionitis and neonatal infection. Early Hum Dev 1994;40:51-8.

40 Itakura A, Kurauchi O, Morikawa S, et al. A prospective study on the relationship between intrapartum maternal group- $B$ streptococcal concentration and signs of infection in neonates. J Obstet Gynaecol Res 1996;22:101-5.

41 Benitz WE, Gould JB, Druzin ML. Risk factors for early-onset group B streptococcal sepsis: estimation of odds ratios by critical literature review. Pediatrics 1999;103:e77.

42 Anderson HR, Cook DG. Passive smoking and sudden infant death syndrome: review of the epidemiological evidence [published erratum appears in Thorax 1999:54:365-6]. Thorax 1997:52:1003-9.

43 McMartin KI, Platt MS, Hackman R, et al. Lung tissue concentrations of nicotine in sudden infant death syndrome (SIDS). J Pediatr 2002;140:205-9.

44 Milerad J, Sundell H. Nicotine exposure and the risk of SIDS. Acta Paediatr Suppl 1993;82(suppl 389):70-2.

45 Hafstrom O, Milerad J, Asokan N, et al. Nicotine delays arousal during hypoxemia in lambs. Pediatr Res 2000;47:646-52.

46 Strachan DP, Cook DG. Health effects of passive smoking. 1. Parental smoking and lower respiratory illness in infancy and early childhood. Thorax 1997:52:905-14.

47 Gurkan F, Kiral A, Dagli E, et al. The effect of passive smoking on the development of respiratory syncytial virus bronchiolitis. Eur J Epidemio 2000;16:465-8.

48 Lanari M, Giovannini M, Giuffre L, et al. Prevalence of respiratory syncytial virus infection in Italian infants hospitalized for acute lower respiratory tract infections, and association between respiratory syncytial virus infection risk factors and disease severity. Pediatr Pulmonol 2002;33:458-65.

49 Altet MN, Alcaide J, Plans $P$, et al. Passive smoking and risk of pulmonary tuberculosis in children immediately following infection. A case-control study. Tuber Lung Dis 1996;77:537-44.

50 Yusuf HR, Rochat RW, Baughman WS, et al. Maternal cigarette smoking and invasive meningococcal disease: a cohort study among young children in metropolitan Atlanta, 1989-1996. Am J Public Health 1999:89:712-17.

51 Kriz P, Bobak M, Kriz B. Parental smoking, socioeconomic factors, and risk of invasive meningococcal disease in children: a population based case-control study. Arch Dis Child 2000;83:117-21.

52 Green GM, Carolin D. The depressant effect of cigarette smoke on the in vitro antibacterial activity of alveolar macrophages. N Engl J Med 1967;276:421-7.

53 Cope GF, Heatley RV. Cigarette smoking and intestinal defences. Gut 1992;33:721-3.

54 Becker S, Soukup JM. Effect of nitrogen dioxide on respiratory viral infection in airway epithelial cells. Environ Res 1999:81:159-66.

55 El Ahmer OR, Essery SD, Saadi AT, et al. The effect of cigarette smoke on adherence of respiratory pathogens to buccal epithelial cells. FEMS Immunol Med Microbiol 1999;23:27-36.

56 Cartwright K. Meningococcal carriage and disease. In: Cartwright K, ed. Meningococcal disease. Chichester: John Wlley \& Sons, 1995:115-46.

57 Strachan DP, Cook DG. Health effects of passive smoking. 4. Parental smoking, middle ear disease and adenotonsillectomy in children. Thorax 1998:53:50-6.

58 Stick SM, Burton PR, Gurrin L, et al. Effects of maternal smoking during pregnancy and a family history of asthma on respiratory function in newborn infants. Lancet 1996;348:1060-4.

59 Dezateux C, Stocks J. Lung development and early origins of childhood respiratory illness. Br Med Bull 1997;53:40-57.
60 Cook DG, Strachan DP, Carey IM. Health effects of passive smoking. 9. Parental smoking and spirometric indices in children [see comments]. Thorax 1998;53:884-93.

61 Cunningham J, Dockery DW, Speizer FE. Maternal smoking during pregnancy as a predictor of lung function in children. Am J Epidemio 1994; 139:1139-52.

62 von Mutius E. Environmental factors influencing the development and progression of pediatric asthma. J Allergy Clin Immunol 2002;109(suppl 6):S525-32.

63 Strachan DP, Cook DG. Health effects of passive smoking. 6. Parental smoking and childhood asthma: longitudinal and case-control studies. Thorax 1998;53:204-12.

64 Mannino DM, Homa DM, Redd SC. Involuntary smoking and asthma severity in children: data from the Third National Health and Nutrition Examination Survey. Chest 2002;122:409-15.

65 Cook DG, Strachan DP. Health effects of passive smoking. 3. Parental smoking and prevalence of respiratory symptoms and asthma in school age children. Thorax 1997;52:1081-94.

66 Coultas DB. Health effects of passive smoking. 8. Passive smoking and risk of adult asthma and COPD: an update. Thorax 1998;53:381-7.

67 Samet JM, Lange P. Longitudinal studies of active and passive smoking. Am J Respir Crit Care Med 1996;154(6 pt 2):S257-65.

68 Kerstiens HA, Rijcken B, Schouten JP, et al. Decline of FEV1 by age and smoking status: facts, figures, and fallacies. Thorax 1997;52:820-7.

69 Strachan DP Cook DG. Health effects of passive smoking. 5. Parental smoking and allergic sensitisation in children [published erratum appears in Thorax 1999;54:366]. Thorax 1998;53:117-23.

70 Eskenazi B, Castorina R. Association of prenatal maternal or postnatal child environmental tobacco smoke exposure and neurodevelopmental and behavioral problems in children. Environ Health Perspect 1999;107:991-1000.

71 Wakschlag LS, Pickett KE, Cook E, et al. Maternal smoking during pregnancy and severe antisocial behavior in offspring: a review. Am J Public Health 2002:92:966-74.

72 Brennan PA, Grekin ER, Mortensen EL, et al. Relationship of maternal smoking during pregnancy with criminal arrest and hospitalization for substance abuse in male and female adult offspring. Am J Psychiatry 2002;159:48-54.

73 Thomas JD, Garrison ME, Slawecki CJ, et al. Nicotine exposure during the neonatal brain growth spurt produces hyperactivity in preweanling rats. Neurotoxicol Teratol 2000;22:695-701.

74 Slotkin TA. Fetal nicotine or cocaine exposure: which one is worse? J Pharmacol Exp Ther 1998;285:931-45.

75 Norman MA, Holly EA, Preston-Martin S. Childhood brain tumors and exposure to tobacco smoke. Cancer Epidemiol Biomarkers Prev 1996;5:85-91.

76 Norman MA, Holly EA, Ahn DK, et al. Prenatal exposure to tobacco smoke and childhood brain tumors: results from the United States West Coast childhood brain tumor study. Cancer Epidemiol Biomarkers Prev 1996;5:127-33.

77 Schuz J, Kaletsch U, Kaatsch P, et al. Risk factors for pediatric tumors of the central nervous system: results from a German population-based case-control study. Med Pediatr Oncol 2001;36:274-82.

78 Filippini G, Maisonneuve P, McCredie M, et al. Relation of childhood brain tumors to exposure of parents and children to tobacco smoke: the SEARCH international case-control study. Surveillance of Environmental Aspects Related to Cancer in Humans. Int J Cancer 2002;100:206-13.

79 Brondum J, Shu XO, Steinbuch M, et al. Parental cigarette smoking and the risk of acute leukemia in children. Cancer 1999;85:1380-8.

80 Sasco AJ, Vainio H. From in utero and childhood exposure to parental smoking to childhood cancer: a possible link and the need for action. Hum Exp Toxicol 1999;18:192-201.

81 Boffetta P, Tredaniel J, Greco A. Risk of childhood cancer and adult lung cancer after childhood exposure to passive smoke: a meta-analysis. Environ Health Perspect 2000:108:73-82.

82 Schuz J, Kaatsch P, Kaletsch U, et al. Association of childhood cancer with factors related to pregnancy and birth. Int J Epidemiol 1999;28:631-9.

83 Feldman W. Evidence-based pediatrics. Evidence-based pediatrics. Hamilton: B.C. Decker Inc., 2000:IX-X

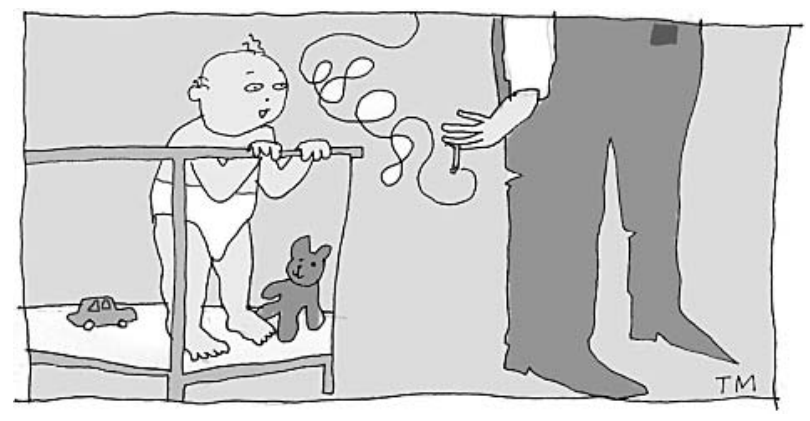

